\title{
Novel Renal Replacement Strategies for the Elimination of Serum Free Light Chains in Patients with Kappa Light Chain NEPHROPATHY
}

\author{
L. Kleeberg1*, S. Morgera2*, C. Jakob ${ }^{1}$, B. Hocher ${ }^{4}$, M. Schneider ${ }^{2}$, H. Peters², S. Rötzerr ${ }^{1}$, C. Müller ${ }^{3}$, \\ M. Kaiser ${ }^{1}$, C. Fleissner ${ }^{1}$, U. Heider ${ }^{1}$, H.-H. Neumayer ${ }^{2}$, O. Sezer ${ }^{1}$ \\ ${ }^{1}$ Department of Hematology and Oncology, ${ }^{2}$ Department of Nephrology, ${ }^{3}$ Institute for Laboratory Medicine and Pathobiochemistry, \\ ${ }^{4}$ Center for Cardiovascular Research/Institute of Pharmacology, \\ Charité - Universitätsmedizin Berlin, Germany
}

\begin{abstract}
Multiple myeloma (MM) is a malignancy with excessive production of monoclonal proteins. At disease presentation $30 \%$ of $\mathrm{MM}$ patients have significant renal impairment which may progress to renal failure requiring dialysis. Besides chemotherapy extracorporeal elimination procedures such as plasma exchange have been applied as adjuvant strategies to eliminate free light chains from circulating blood, however the efficacy was poor with older techniques. We report about a highly efficient method to eliminate serum free light chain (sFLC) using a newly designed protein leaking membrane in patients suffering from sFLC induced acute renal failure. The protein leaking membrane (HCO 1100) is characterized by increased pore size facilitating elimination of middle molecules such as sFLC kappa (22.5 kD). The HCO 1100 membrane was applied in a hemodialysis and hemodiafiltration mode and compared to standard procedures (high flux hemodialysis, hemodiafiltration and plasma exchange). Hemodiafiltration with the protein leaking membrane HCO 1100 was superior to all other extracorporeal replacement strategies in eliminating sFLC-kappa from circulating blood. A median blood reduction rate of $40.8 \%$ (range $13.9 \%-66.4 \%$ ) was achieved during hemodiafiltration. The corresponding peak clearance rate was $25 \mathrm{ml} / \mathrm{min}$. Importantly, the poorest elimination rate was achieved by plasma exchange followed by standard high flux hemodialysis. Extracorporeal elimination strategies with the protein leaking membrane HCO 1100 may be a promising adjuvant treatment strategy for patients with sFLC nephropathy requiring dialysis. Hemodiafiltration and to lesser extend also hemodialysis with the HCO 1100 hemofilter are able to eliminate substantial amounts of sFLC kappa in MM patients.
\end{abstract}

Key words: Serum free light chains, multiple myeloma, acute renal failure, hemodialysis, hemofiltration, plasmapheresis.

* Lorenz Kleeberg and Stanislao Morgera contributed equally to this work.

\section{INTRODUCTION}

Multiple myeloma (MM) is a B-cell neoplasia which is characterized by an malignant proliferation of aberrant plasma cells in the bone marrow. Renal impairment and bone resorption are among the most important consequences of this disease [1-3]. Novel treatment options are urgently needed and are being developed [4-6]. In MM malignant plasma cells usually produce excessive amounts of monoclonal proteins, which may involve intact immunoglobulins or serum free light chains (sFLC) or both. In a study of 1027 patients with newly diagnosed MM, Kyle et al. reported that serum creatinine level was increased in almost half of the patients [7]. sFLC play a crucial role in MM induced renal damage and are probably the most important cause of renal failure in these patients. In healthy individuals production of sFLC is approximately $500 \mathrm{mg} /$ day. This "physiologic" amount of sFLC gets rapidly cleared and degraded by the kidneys. However, sFLC production in MM can reach 30g/day exceeding the clearance capacity of the kidneys. Major cause of renal failure in $\mathrm{MM}$ is cast nephropathy. sFLC are normally transported to the interstitium of the kidney via specific receptors in the proximal tubule. Overload of these receptors by excessive amounts of sFLC results in an overflow of them to the distal tubule. sFLC entering the distal tubule usually bind to uromucoid (Tamm-Horsfall protein) and form casts, which obstruct tubular fluid flow, leading to disruption of the basement membrane and interstitial damage [8-12].

The amount of sFLC necessary to cause renal impairment has recently been studied by Nowrouisan et al. [13]. The median serum concentration associated with overflow proteinuria and hence tubular damage were $113 \mathrm{mg} / \mathrm{l}$ for kappa and $278 \mathrm{mg} / 1$ for lambda light chain, respectively. Thus, this level corresponds to a daily production of light chains about $5 \mathrm{~g}$.

Reduction of sFLC levels therefore represents a potential strategy to improve renal function in acute renal failure in MM. In this regard prompt initiation of an effective chemotherapy protocol is a precondition 
for success, but additional supportive treatment options are increasingly discussed in this regard. Studies were initiated to investigate the use of plasma exchange in patients with MM and acute renal failure but failed to show any significant benefit on renal function $[14,15]$.

In the present manuscript we report on a new type of renal replacement therapy (RRT), namely RRT using a protein leaking membrane. Protein leaking membranes are characterized by an increased pore size of the dialyzer membrane promoting the elimination of middle sized molecules such as sFLC. These membranes were initially developed to improve the clearance capacity for inflammatory mediators in critically ill septic patients. Particularly one hemofilter, the HCO1100 has been extensively studied in the regard $[16,17]$. In this paper we analyzed the efficacy of the protein leaking membrane HCO1100 to eliminate sFLC in kappa light chain MM patients with acute renal failure necessitating RRT. The elimination capacity of the HCO1100 was studied in the hemodialysis and hemodiafiltration mode and was compared to standard hemodialysis procedures as well as to plasma exchange.

\section{Patients AND Methods}

Four consecutive patients with kappa light chain MM were included in this study. All patients necessitated RRT due to acute renal failure. Indication for renal replacement was based on clinical and laboratory grounds. Baseline laboratory evaluation included blood creatinine, estimated creatinine clearance (MDRD formula), urea, acid base and electrolyte household.

Before and after each renal replacement session sFLC levels were measured using latex-enhanced nephelometric immunoassays (The Binding Site, Schwetzingen, Germany) adapted to the BN Prospec Nephelometer (Dade-Behring, Eschborn, Germany). The interassay coefficients of variation were $5.1 \%$ at $14.3 \mathrm{mg} / \mathrm{l}$ for the sFLC kappa and $3.6 \%$ at $28.1 \mathrm{mg} / 1$ for the sFLC lambda assay with control sera $(\mathrm{n}=10)$ provided by The Binding Site.

Hemodialysis and hemodiafiltration procedures were performed with a dialysis device allowing the online preparation of ultrapure hemofiltration replacement fluids if required (AK200S, Gambro Dialysatoren $\mathrm{GmbH}$, Hechingen, Germany). Polyamide high flux hemofilter (Polyflux 140H, Polyflux 210H, steam sterilized, Gambro Dialysatoren $\mathrm{GmbH}$, Hechingen, Germany) were used for standard hemodialysis. For standard hemodiafiltration the Polyflux $210 \mathrm{H}$ was used. Membrane specifications for the high flux hemofilter Polyflux 140H (PF 140H) and Polyflux $210 \mathrm{H}$ (PF 210H) are as follows: effective surface area $1.4 \mathrm{qm}$ for PF $140 \mathrm{H}$ and $2.1 \mathrm{qm}$ for PF $210 \mathrm{H}$, wall thickness $50 \mu \mathrm{m}$, inner diameter $215 \mu \mathrm{m}$, membrane pore size $\sim 5 \mathrm{~nm}$, ultrafiltration coefficient $60 \mathrm{(ml} / \mathrm{h}$, $\mathrm{mmHg}$ ) for $\mathrm{PF} 140 \mathrm{H}$ and $85(\mathrm{ml} / \mathrm{h}, \mathrm{mmHg})$ for $\mathrm{PF}$ $210 \mathrm{H}$, cut off point $30-40 \mathrm{kD}$, sieving coefficient for vitamin B12 (molecular weight $1.35 \mathrm{kD}$ ) and inulin (molecular weight $5.20 \mathrm{kD}$ ) 1.0, for $\beta 2$ microglobulin (molecular weight $11.8 \mathrm{kD}$ ) 0.7 .
For RRT (either hemodialysis or hemodiafiltration) with the protein leaking membrane a newly designed high cut off hemofilter, the polyamide HCO 1100 hemofilter (HCO 1100, effective surface area $1.1 \mathrm{qm}$, steam sterilized, Gambro Corporate Research, Hechingen, Germany) was used. The high cut off hemofilter is characterized by an increased pore diameter of $\sim 10$ $\mathrm{nm}$ with a membrane thickness of $50 \mu \mathrm{m}$ and an internal diameter of $215 \mu \mathrm{m}$. The in vivo cut off point of the membrane is approximately $60-80 \mathrm{kD}$. The hemofilter has been designed to increase the in-vivo permeability for substances in the molecular weight range up to $60 \mathrm{kD}$. Basic features of this new hemofilter have been recently described [18-21].

Whenever the protein leaking membrane was applied regular controls of plasma albumin and total protein were performed (pre- and post dialysis). In case of high transmembrane protein losses a balanced substitution of human albumin was done. For all renal replacement therapies blood flow rate was uniformly set at $200 \mathrm{ml} / \mathrm{h}$, dialysate flow rate was $500 \mathrm{ml} / \mathrm{min}$. Dialysis time varied between 4 to 6 hours. The ultrafiltration rate was based on the individual fluid balance of the patients.

In a subgroup of patients sFLC kappa - clearances in the initial phase (10 min after start of treatment) and at the end of therapy were calculated as follows: clearance $(\mathrm{ml} / \mathrm{min})=$ dialysate concentration of FLC / inlet serum concentration of FLC $\mathrm{x}$ dialysate flow rate.

A roller blood pump device was used for plasma exchange (BSM 22, Gambro Hospal Germany). A standard plasmafilter (Gambro PF 2000N, Gambro, Lund, Sweden) was chosen. $2500 \mathrm{ml}$ of fresh frozen plasma were given in exchange during a $2.5 \mathrm{~h}$ session. Blood flow rate was set at $100 \mathrm{ml} / \mathrm{min}$.

\section{STATISTICS}

Data were analyzed by non-parametric tests. Paired data were compared using the Wilcoxon rank sum test, unpaired data by the Mann-Whitney-U-test. Results were expressed as median and range. A p-value below 0.05 was considered significant. The statistical program SPSS 12 (SPSS Inc., Chicago, Illinois) was used for analysis.

\section{RESULTS}

\section{Patients Characteristics}

Patient 1 was a 73-year-old male who had previously received 6 cycles of chemotherapy with melphalan and prednisolone. At the time of admission he had acute renal failure with a creatinine level of 11.3 $\mathrm{mg} / \mathrm{dl}$ (eGFR $5 \mathrm{ml} / \mathrm{min}$ ). Baseline sFLC kappa were $2910 \mathrm{mg} / \mathrm{l}$. Chemotherapy with adriamycin and dexamethasone was initiated. In order to reduce the amount of sFLC two treatment sessions of plasma exchange were performed (Fig. 1). For uremia control RRT had to be started. Six sessions of high flux hemodialysis (Fig. 2) with a median ultrafiltration rate of $1680 \mathrm{ml}$ (range $900-2600 \mathrm{ml}$ ) per session were applied. 


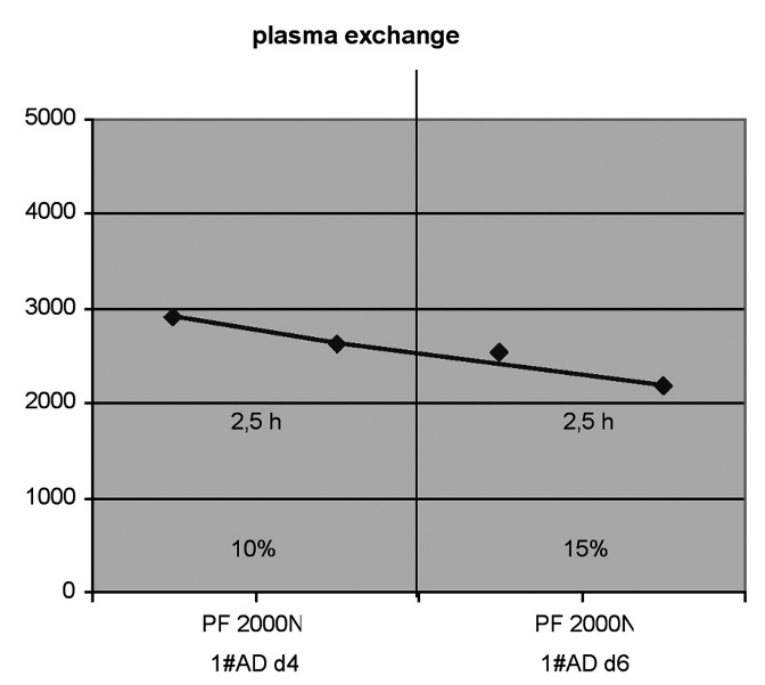

1\#AD: First cycle of adriamycin and dexamethasone

Fig. 1. Reduction rate (\%) of sFLC kappa during two sessions of plasma exchange. Treatment time was 2.5 hour per session (Patient 1).

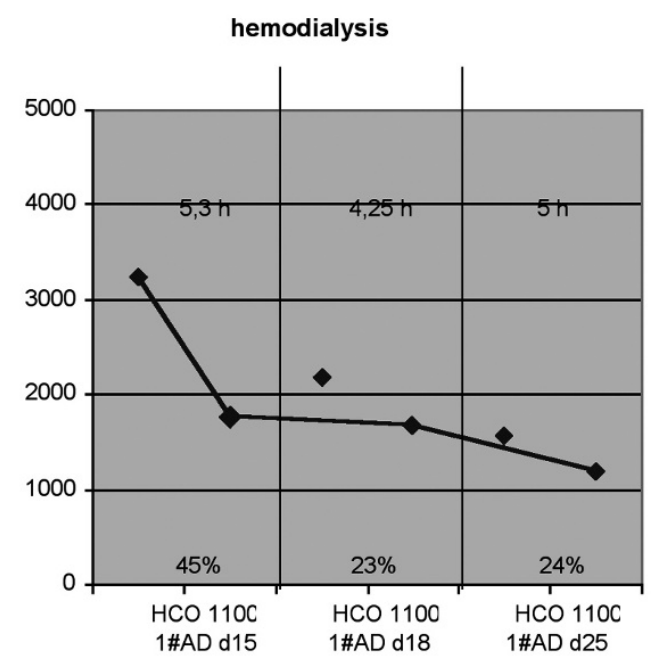

1\#AD: First cycle of adriamycin and dexamethasone

Fig. 3. Reduction rate (\%) of sFLC kappa with hemodialysis using the protein leaking membrane HCO1100. Treatment time is shown in hours (Patient 2).

standard hemodialysis

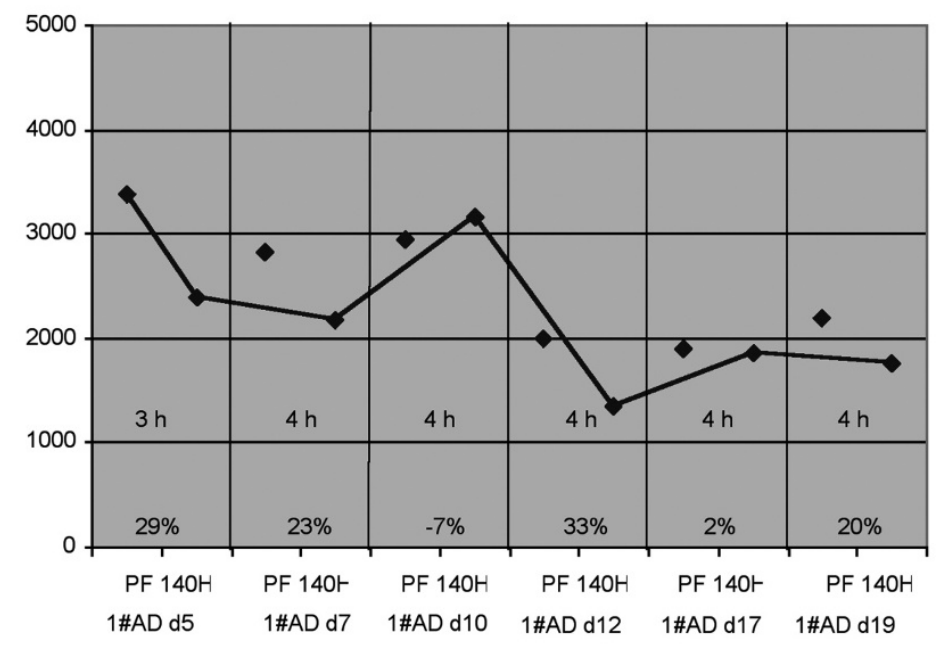

1\#AD: First cycle of adriamycin and dexamethasone
Fig. 2. Reduction rate (\%) of sFLC kappa with hemodialysis using the high flux membrane PF $140 \mathrm{H}$. Treatment time is shown in hours (Patient 1).
Patient 2 was a 70 -year-old female who had developed MM induced acute renal failure with a creatinine of $3.4 \mathrm{mg} / \mathrm{dl}$ and an estimated GFR of $14 \mathrm{ml} / \mathrm{min}$ at hospital admission. sFLC kappa were $3240 \mathrm{mg} / \mathrm{l}$. Chemotherapy was started with adriamycin and dexamethasone. The patient was treated with hemodialysis thrice weekly using a standard high flux hemofilter as well as the protein leaking membrane on day 15, 18 and 25 (Fig. 3). Dialysis time was 5 hours per session. The median ultrafiltration rate was $700 \mathrm{ml}$ (range 600$1600 \mathrm{ml})$.

Patient 3 was a 61-year-old woman with a long known history of light chain MM disease. Previously, this patient had been treated with various chemotherapy protocols, including high-dose chemotherapy with autologous stem cell transplantation, thalidomide and dexamethasone, bortezomib, lenalidomide and dexamethasone. She was admitted to the hospital due to MM induced acute renal failure. At admission creatinine was $5.4 \mathrm{mg} / \mathrm{dl}$ (eGFR $9 \mathrm{ml} / \mathrm{min})$. Baseline sFLC kappa were $13,300 \mathrm{mg} / \mathrm{l}$. Treatment was started with three sessions of hemodialysis using the protein leaking membrane (Fig. 4). Median ultrafiltration was $3300 \mathrm{ml}$ (range 2200-4000 ml). After the third hemodialysis session chemotherapy with adriamycin and dexamethasone was started. The hemodialysis procedures were followed by 5 sessions of hemodiafiltration using the same hemofilter (Fig. 5). Median ultrafiltration was $2950 \mathrm{ml}(2650$ - $4600 \mathrm{ml})$. After hemodiafiltration 4 sessions of standard hemodialysis using a standard hemofilter (PF 140H, Gambro) were performed (Fig. 4). Median ultrafiltration was $400 \mathrm{ml}(300-1000 \mathrm{ml})$.

Although chemotherapy was promptly initiated, the patient developed progressive disease with an increase of sFLC kappa from $5740 \mathrm{mg} / 1$ at admission to 6640 $\mathrm{mg} / 1$ after the first cycle of chemotherapy. Thus, 


\section{hemodialysis}

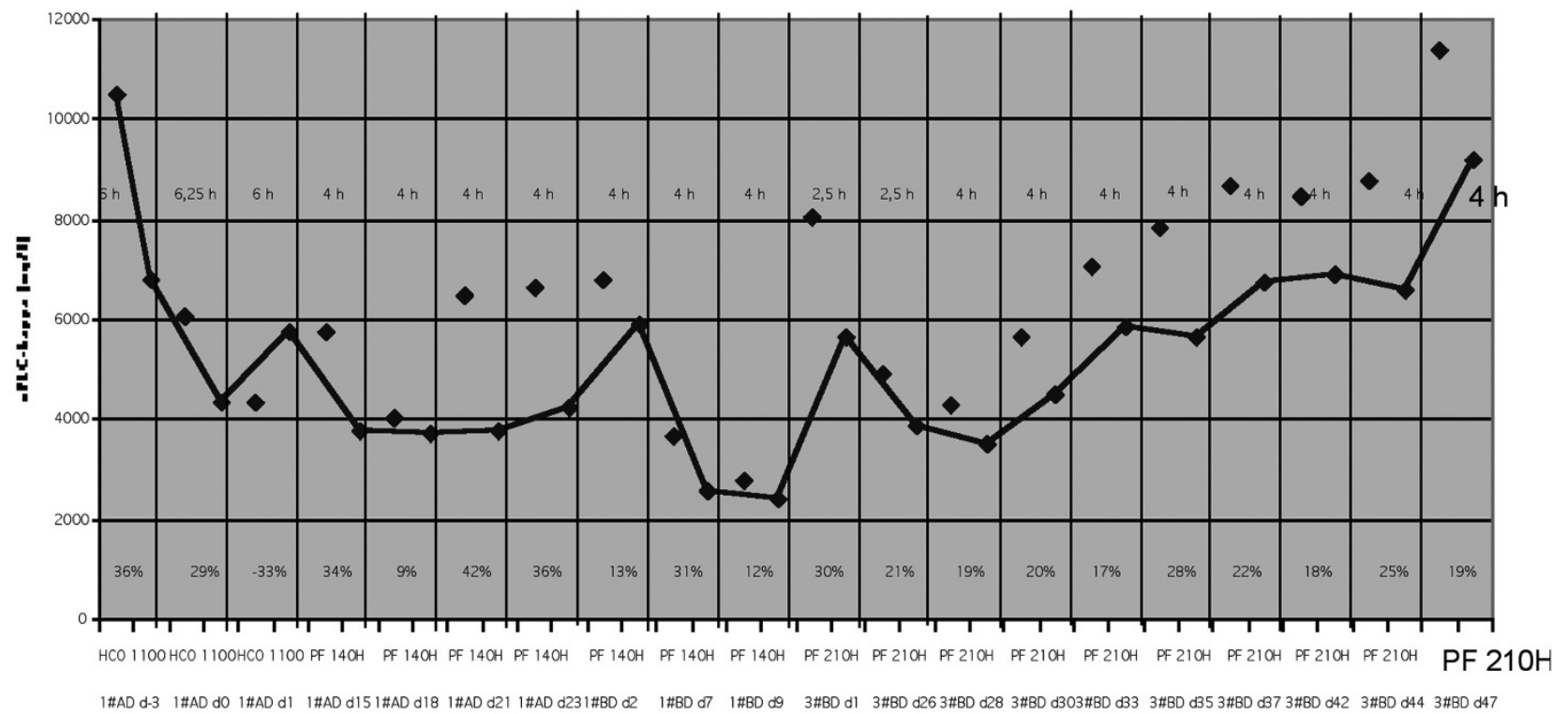

1\#AD: First cycle of adriamycin and dexamethasone

$1 \# B D$ : First cycle of bortezomib and dexamethason

3\#BD: Third cycle of bortezomib and dexamethason

Fig. 4. Reduction rate (\%) of sFLC kappa by hemodialysis. Treatment time is shown in hours (Patient 3).

\section{hemodiafiltration}

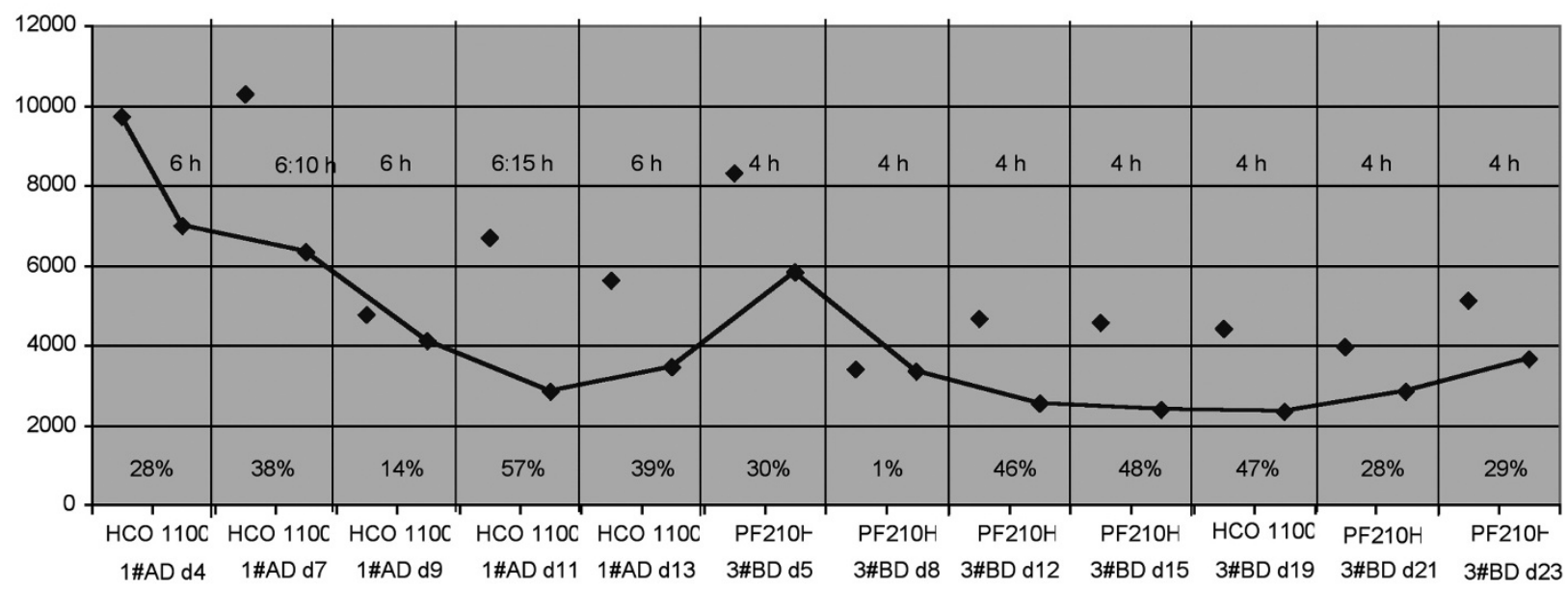

1\#AD: First cycle of adriamycin and dexamethasone

3\#BD: Third cycle of bortezomib and dexamethasone

Fig. 5. Reduction rate (\%) of sFLC kappa with hemodiafiltration applying the HCO 1100 and PF210H hemofilter. Treatment time is shown in hours (Patient 3).

chemotherapy was switched to bortezomib and dexamethasone. Contemporaneously hemodialysis applying a standard high flux hemofilter (Fig. 4) was performed. A detailed sequence of the hemofilters used in this patient is given in Figures 4 and 5.

Patient 4 was a 51 year old woman. This previously untreated patient was admitted to our hospital due to hypercalcaemia of $3.7 \mathrm{mmol} / 1$ and acute renal failure with a creatinine of $5.3 \mathrm{mg} / \mathrm{dl}$ (eGFR $12 \mathrm{ml} / \mathrm{min}$ ).
Serum FLC kappa was $15,100 \mathrm{mg} / \mathrm{l}$ at presentation. Hemodialysis using the protein leaking hemofilter was immediately started. A total of 9 hemodialysis sessions with a median ultrafiltration rate of $415 \mathrm{ml}$ (range 0$1500 \mathrm{ml}$ ) were performed. Simultaneously chemotherapy with adriamycin and dexamethasone was initiated (Fig. 6). Furthermore the patient received 7 sessions of hemodiafiltration (HC1100) with a median ultrafiltration of $550 \mathrm{ml}$ (range $0-1500 \mathrm{ml}$ ) (Fig. 7). However, 


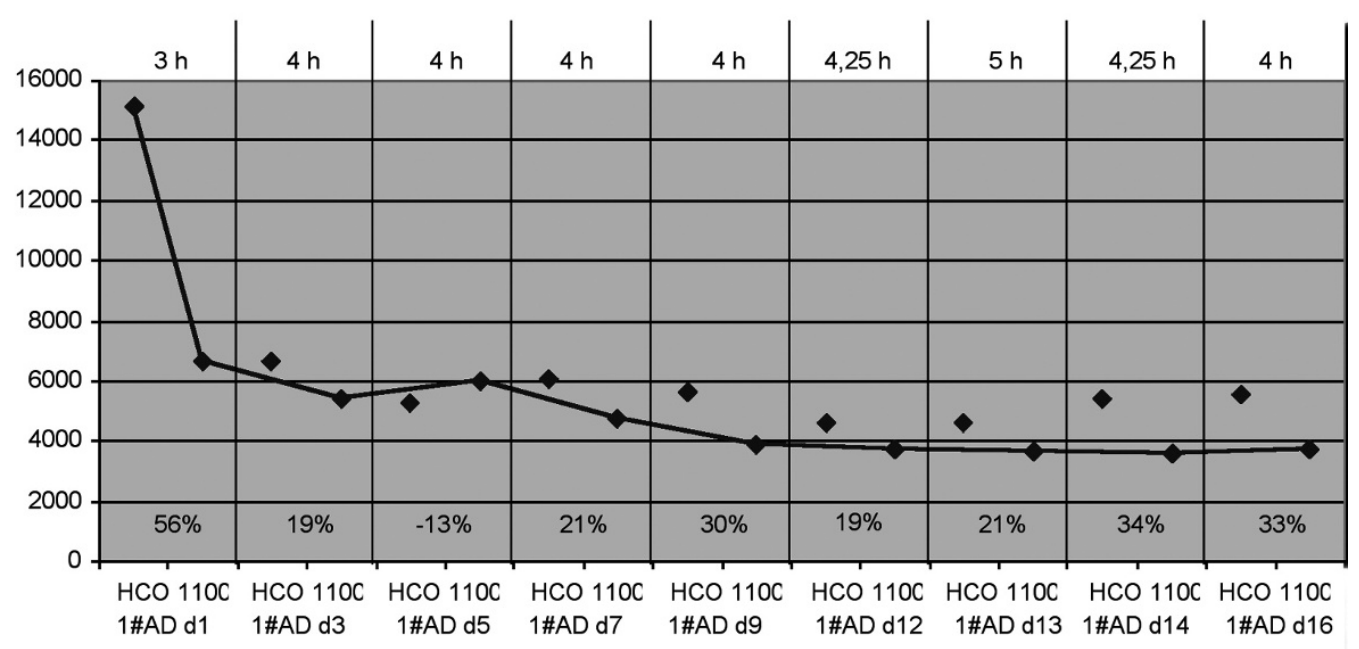

1\#AD: First cycle of adriamycin and dexamethasone

Fig. 6. Elimination of sFLC kappa with hemodialysis using protein leaking filter. Treatment time is shown in hours (Patient 4).

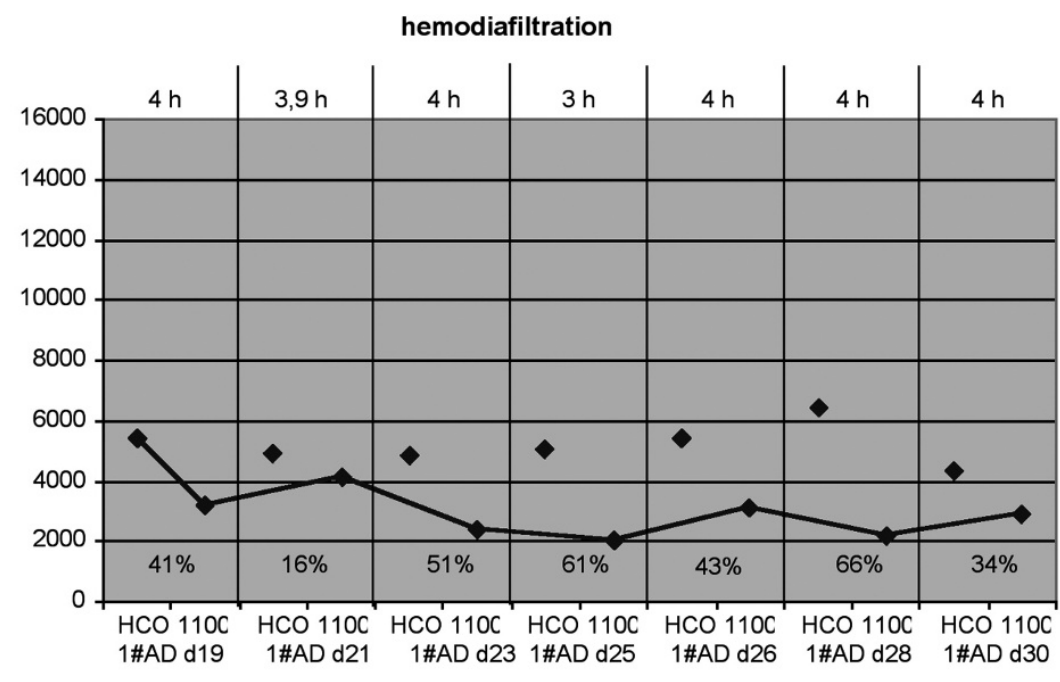

1\#AD: First cycle of adriamycin and dexamethasone
Fig. 7. Elimination of sFLC kappa using hemodiafiltration with protein leaking hemofilter HCO 1100. Treatment time is shown in hours (Patient 4).

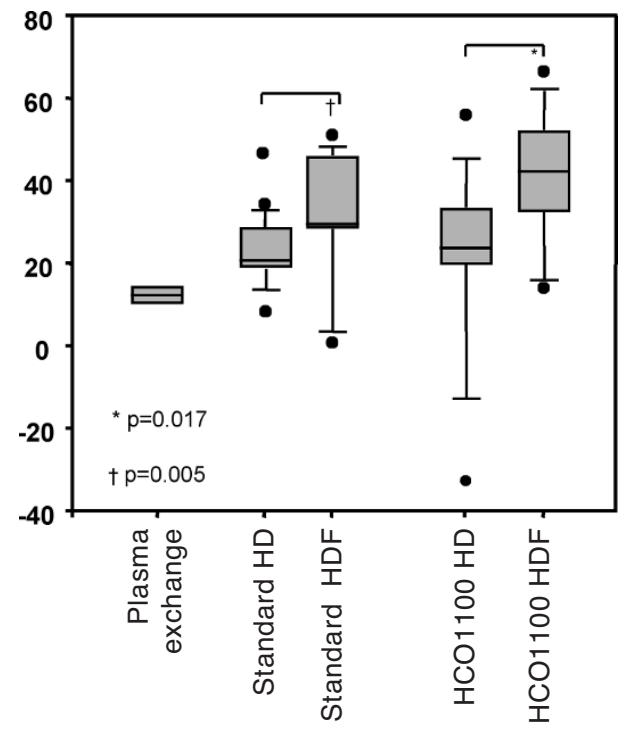

Fig. 8. Box-Whiskers-Plot: Summary of median sFLC kappa reduction rates by different renal replacement strategies.
sFLC increased from 6270 to $6450 \mathrm{mg} / 1$ indicating an uncontrolled and progressive disease. Thus, chemotherapy was switched to bortezomib and dexamethasone.

\section{sFLC Reduction Rates and Clearance}

Our data reveal that hemodiafiltration with the protein leaking membrane HCO 1100 was superior to all other extracorporeal replacement strategies in eliminating sFLC from circulating blood (Fig. 8). With the protein leaking membrane HCO 1100 a median reduction rate of $40.8 \%$ (range $13.9 \%$ - 66.4\%) was achieved during hemodiafiltration and $23.7 \%$ (range $-32.9 \%-55.8 \%$ ) during hemodialysis $(\mathrm{p}=0.017$ ) (Fig. 8). Eliminating the extremes (there were two protein leaking membrane hemodialysis sessions were the sFLC increased during dialysis, probably due to an highly active disease) significance still remained in favor for the hemodiafiltration mode $(\mathrm{p}=0.04)$. Of interest, lowest sFLC kappa elimination rates were achieved with plasma exchange. The percentage decline of sFLC kappa during plasma exchange was only $14.5 \%$ and $9.9 \%$, re- 
spectively (Fig. 1). In the same patient high flux hemodialysis achieved a median reduction rate of $21.4 \%$ (range $-7.4 \%-32.7 \%$, Fig. 2).

The median overall reduction rate for conventional high flux hemodialysis was $21.2 \%$ (range -7,5\% $41.5 \%)$. Comparing the small (PF $140 \mathrm{H})$ versus the large surface area membrane $(\mathrm{PF} 210 \mathrm{H})$ revealed a slight, but statistically not significant advantage in $\mathrm{fa}-$ vor for the large surface area membrane $(p=0.66)$. Nevertheless, a significant difference was found between standard high flux hemodiafiltration (PF 210H) and hemodialysis (PF 210H), in favor for the hemodiafiltration mode ( $\mathrm{p}=0.005)$ (Fig. 8).

In parallel best clearance rates were achieved during hemodiafiltration with the protein leaking membrane followed by hemodialysis with the protein leaking membrane. Maximum clearances were achieved in the initial phase of the treatment with values reaching up to $25 \mathrm{ml} / \mathrm{min}$ during HCO 1100 compared to 5 $\mathrm{ml} / \mathrm{min}$ during conventional therapy (PF 210H). However, even when the protein leaking membrane was used clearance rates declined to around $10 \mathrm{ml} / \mathrm{min}$ at 4 hours.

\section{SAFETY CRITERIA}

Treatments with the protein leaking membrane $\mathrm{HCO}$ 1100 were well tolerated hemodynamically. Blood pressure drops were equally distributed between standard high flux treatments and treatments performed with the protein leaking membrane.

Median albumin values before and after treatment with the protein leaking membrane were 3.3 (range 3.1-3.7) and 3.4 (range 3.3-3.89), respectively. Values did not differ to those obtained during standard high flux hemodialysis or hemodiafiltration. Albumin substitution was not necessary.

\section{DisCUSSION}

In this study we analyzed different modes of extracorporeal elimination techniques for reducing sFLC kappa in patients with kappa light chain MM associated nephropathy requiring dialysis. We compared a novel type of hemofilter, a so-called protein leaking membrane, applied in a hemodialysis and hemodiafiltration mode to standard procedures such as high flux hemodialysis and hemodiafiltration as well as plasma exchange.

We found a superiority in favor for the protein leaking membrane particularly when applied in the hemodiafiltration mode. Plasma exchange achieved the lowest effects on sFLC. High flux hemofilters, particularly high flux membranes with a large surface area reached surprisingly good reduction rates for sFLC kappa. However, when the clearance rates were analyzed, a significant advantage in favor for the protein leaking membrane was found. Up to 10 fold higher clearance rates were achieved with the protein leaking membrane compared to the high flux hemofilter (PF $210 \mathrm{H})$.

Kappa light chains have a molecular weight of around $22.5 \mathrm{kD}$. They are normally cleared in $2-4$ hours at $40 \%$ of the glomerular filtration rate. Howev- er, removal may be significantly prolonged in patients with renal failure and can reach up to 2-3 days in MM patients in complete renal failure [22,23]. Free light chains are distributed in similar concentrations in serum, extra-vascular compartment and in tissue edema fluid [24]. The intra-vascular compartment probably contains only $15-20 \%$ of the total amount. Thus, redistribution from the interstitium into the vascular compartment occurs which makes a long extracorporeal treatment session necessary for an effective removal of sFLC. Clark et al. studied the effects of plasma exchange on clinical course of MM patients [15]. They performed 5 to 7 plasma exchanges in their patients and found that it did not reduce a composite outcome of death, dialysis dependence, or glomerular filtration rate at 6 months. However, they initiated the study before the routine availability of the immunoglobulin free light chain assay, thus sFLC were not investigated and subgroup analyses for light chain diseases could not be performed. Very recently, Cserti and co-workers studied sFLC concentration in two patients and found that plasma exchange failed to effectively lower sFLC levels [25]. Plasma exchange was performed using a continuous-flow cell separator. In our study plasma exchange was studied in one patient. The median reduction rate for sFLC kappa was only $12,3 \%$. The plasma exchange volume was $2.5 \mathrm{~L}$, which is a standard dose for plasma exchange. Based on this finding and having in mind the results from Clark and co-workers we decided not to proceed with plasma exchange in light chain MM since the low serum reduction rates do not compensate for the potential risks (allergic reaction, infections etc) [15].

Hemodialysis with newly designed protein leaking membranes may represent an alternative strategy to clear sFLC more effectively. Due to an increased pore size of these membranes the elimination of middle sized molecules including sFLC is eased. Very recently Hutchison and co-workers studied the impact of different protein leaking membranes on the capacity to clear sFLC [26]. Hemodialysis was treatment modality in all patients. Best results were achieved with the Gambro HC 1100 membrane. Excellent clearance rates for both kappa and lambda light chains were reported which translated in a significant removal of sFLC in light chain MM patients with acute renal failure. Serum-FLC could be reduced by 35 to $70 \%$.

In the present study, we analyzed the Gambro HCO 1100 membrane in the hemodialysis and hemodiafiltration mode extending the results of Hutchison and co-workers. We found that the hemodiafiltration mode had an advantage over the hemodialysis mode. The maximum reduction rate for sFLC kappa was 66\% which is line with the data reported by Hutchison.

Interestingly, we observed a high variability in the inter- and intra-patient reduction rate for sFLC kappa during HCO 1100 RRT which is best explained by a variable activity status of the underlying disease. While patient 2 and 4 had a more or less constant sFLC kappa reduction rate of around 25 to $30 \%$ over time (indicating a stable disease activity), patient 3 showed an increase in sFLC kappa on day 1 of the first cycle of chemotherapy with adriamycin and dexamethasone from $4320 \mathrm{mg} / 1$ before starting HCO 1100 dialysis to 
$5740 \mathrm{mg} / \mathrm{l}$ at the end of the treatment session. Values increased even further in the dialysis free interval and reached $9739 \mathrm{mg} / 1$ on the consecutive dialysis day (predialysis value). The missing fall in sFLC kappa can be clearly interpreted as a sign of rapid disease progression. A switch in chemotherapy to bortezomib was done which resulted in a prompt decline in sFLC kappa. A highly effective chemotherapy is a precondition for treating MM associated nephropathy and must be initiated simultaneously to the RRT. A further example for this is patient 4 . After the first cycle of chemotherapy with adriamycin and dexamethasone sFLC decreased from $6270 \mathrm{mg} / 1$ (day1) to $3500 \mathrm{mg} / 1$ (day14), but then increased up to $6450 \mathrm{mg} / 1$ (day 28) again. Thus, we changed the regimen to bortezomib and dexamethasone. At day 16 after starting this chemotherapy regime sFLC dropped to $48.8 \mathrm{mg} / \mathrm{l}$. Here, a combination of an effective chemotherapy and hemodialysis led to a very good result.

Importantly, the observed rebound phenomenon after RRT also results from the distribution of sFLC into the different body compartments [24]. Only around $20 \%$ of the total amount of sFLC are found in circulating blood whereas $80 \%$ lay in the so called "third compartment". Redistribution processes have to take place before these "trapped" sFLC can be eliminated. Hence, sustained elimination procedures are required.

RRT with some protein leaking membranes can lead to substantial transmembrane protein losses particularly when used on a extended daily base as propagated by Hutchison et al. [26]. However, in our study population a severe protein depletion was not observed.

In conclusion, extracorporeal elimination strategies with the protein leaking membrane HCO 1100 may be a new and promising adjuvant treatment strategy for patients with sFLC nephropathy requiring dialysis. Hemodiafiltration and to lesser extend also hemodialysis with the HCO 1100 hemofilter are able to eliminate substantial amounts of sFLC kappa in MM patients. However, a rebound phenomenon is observed which not only demands a prolonged and repeated treatment strategy but also an effective chemotherapy protocol as a precondition for renal recovery.

\section{REFERENCES}

1. Sezer O, Heider U, Zavrski I, Kühne CA, Hofbauer LC (2003) RANK ligand and osteoprotegerin in myeloma bone disease. Blood 101:2094-2098

2. Heider U, Fleissner C, Zavrski I, Kaiser M, Hecht M, Jakob C, Sezer O (2006) Bone markers in multiple myeloma. Eur J Cancer 42:1544-1553

3. Jakob C, Sterz J, Zavrski I, Heider U, Kleeberg L, Fleissner C, Kaiser M, Sezer O (2006) Angiogenesis in Multiple Myeloma. Eur J Cancer 42:1581-1590

4. Zavrski I, Kleeberg L, Kaiser M, Fleissner C, Heider U, Sterz J, Jakob C, Sezer O (2007) Proteasome as an emerging therapeutic target in cancer. Curr Pharm Design 13:471-485.

5. Sezer O, Vesole D, Singhal S, Richardson P, Stadtmauer E, Jakob C, Boral A, Esseltine DL, Mehta J (2006) Bortezomib-induced tumor lysis syndrome in multiple myeloma. Clin Lymphoma Myeloma 7:233-235

6. Kaiser M, Zavrski I, Sterz J Jakob C, Fleissner C, Kloetzel PM, Sezer O, Heider U (2006) The effects of the histone deacetylase inhibitor valproic acid on cell cycle, growth suppression and apoptosis in multiple myeloma. Haematologica 91:248-251

7. Kyle RA, Gertz MA, Witzig TE, Lust JA, Lacy MQ, Dispenzieri A, Fonseca R, Rajkumar SV, Offord JR, Larson DR, Plevak ME, Therneau TM, Greipp PR (2003) Review of 1027 patients with newly diagnosed multiple myeloma. Mayo Clin Proc 78:21-33

8. Clark AD, Shetty A, Soutar R (1999) Renal failure and multiple myeloma: pathogenesis and treatment of renal failure and management of underlying myeloma. Blood Rev 13:79-90

9. Huang ZQ, Kirk KA, Connelly KG, Sanders PW (1993) Bence Jones proteins bind to a common peptide segment of Tamm-Horsfall glycoprotein to promote heterotypic aggregation. J Clin Invest 92:2975-2983

10. Misiani R, Remuzzi G, Bertani T, Licini R, Levoni P, Crippa A, Mecca G (1979) Plasmapheresis in the treatment of acute renal failure in multiple myeloma. Am J Med 66: 684-688

11. Picken MM, Shen S (1994) Immunoglobulin light chains and the kidney: an overview. Ultrastruct Pathol 18:105112

12. Sanders PW, Herrera GA (1993) Monoclonal immunoglobulin light chain-related renal diseases. Semin Nephrol 13:324-341

13. Nowrousian MR, Brandhorst D, Sammet C Kellert M, Daniels R, Schuett P, Poser M, Mueller S, Ebeling P, Welt A, Bradwell AR, Buttkereit U, Opalka B, Flasshove M, Moritz T, Seeber S (2005) Serum free light chain analysis and urine immunofixation electrophoresis in patients with multiple myeloma. Clin Cancer Res 11:8706-8714

14. Johnson WJ, Kyle RA, Pineda AA, O'Brien PC, Holley KE (1990) Treatment of renal failure associated with multiple myeloma. Plasmapheresis, hemodialysis, and chemotherapy. Arch Intern Med 150:863-869

15. Clark WF, Stewart AK, Rock GA, Sternbach M, Sutton DM, Barrett BJ, Heidenheim AP, Garg AX, Churchill DN for Canadian Apheresis Group (2005) Plasma Exchange When Myeloma Presents as Acute Renal Failure. A Randomized, Controlled Trial. Ann Intern Med 143:777-784

16. Morgera S, Haase M, Kuss T Vargas-Hein O, Zuckermann-Becker H, Melzer C, Krieg H, Wegner B, Bellomo R, Neumayer HH (2006) Pilot study on the effects of high cutoff hemofiltration on the need for norepinephrine in septic patients with acute renal failure. Crit Care Med 34:2099-2104

17. Morgera S, Slowinski T, Melzer C Sobottke V, VargasHein O, Volk T, Zuckermann-Becker H, Wegner B, Muller JM, Baumann G, Kox WJ, Bellomo R, Neumayer HH (2004) Renal replacement therapy with high-cutoff hemofilters: Impact of convection and diffusion on cytokine clearances and protein status. Am J Kidney Dis 43:444-453

18. Morgera S, Klonower D, Rocktaschel J, Haase M, Priem F, Ziemer S, Wegner B, Göhl H, Neumayer HH (2003) TNF-alpha elimination with high cut-off haemofilters: a feasible clinical modality for septic patients? Nephrol Dial Transplant 18:1361-1369

19. Morgera S, Rocktaschel J, Haase M Lehmann C, von Heymann C, Ziemer S, Priem F, Hocher B, Gohl H, Kox WJ, Buder HW, Neumayer HH (2003) Intermittent high permeability hemofiltration in septic patients with acute renal failure. Intensive Care Med 29:1989-1995

20. Morgera S, Slowinski T, Melzer C Sobottke V, VargasHein O, Volk T, Zuckermann-Becker H, Wegner B, Muller JM, Baumann G, Kox WJ, Bellomo R, Neumayer HH (2004) Renal replacement therapy with high cut-off hemofilters : Impact of convection and diffusion on cytokine clearances and protein status. Am J Kidney Dis 43:444-453 
21. Lee WC, Uchino S, Fealy N, Baldwin I, Panagiotopoulos S, Goehl H, Morgera S, Neumayer HH, Bellomo R (2004) Super high flux hemodialysis at high dialysate flows: an ex vivo assessment. Int J Artif Organs 27:24-28

22. Mead GP, Carr-Smith HD, Drayson MT, Morgan GJ, Child JA, Bradwell AR (2004) Serum free light chains for monitoring multiple Myeloma. Br J Haematol 126:348354

23. Pratt G, Mead GP, Godfrey KR, Hu Y, Evans ND, Chappell MJ, Lovell R, Bradwell AR (2006) The tumor kinetics of multiple myeloma following autologous stem cell transplantation as assessed by measuring serum-free light chains. Leuk Lymphoma 47:21-28

24. Takagi K, Kin K, Itoh Y, Enomoto H, Kawai T (1980) Human alpha 1-microglobulin in various body fluids. J Clin Pathol 33:786-791

25. Cserti C, Haspel R, Stowell C, Dzik W (2007) Light-chain removal by plasmapheresis in myeloma-associated renal failure. Transfusion 47:511-514
26. Hutchison CA, Cockwell P, Reid S, Chandler K, Mead GP, Harrison J, Hattersley J, Evans ND, Chappell MJ, Cook M, Goehl H, Storr M, Bradwell AR (2007) Efficient Removal of Immunoglobulin Free Light Chains by Hemodialysis for Multiple Myeloma: In Vitro and In Vivo Studies. J Am Soc Nephrol 18: 886-895

Received: November 28, 2008 / Accepted: December 3, 2008

Address for correspondence:

Priv. Doz. Dr. Stanislao Morgera

Department of Nephrology

Charité - Universitätsmedizin Berlin

Charitéplatz 1

10117 Berlin

Germany

Tel.: +49-30/450-514002

Fax: $\quad+49-30 / 450-514902$

E-mail: stanislao.morgera@charite.de 